\title{
Medical Education Scholars Program: an approach to development of scholars in education in Tehran University of Medical Sciences
}

This article was published in the following Dove Press journal:

Advances in Medical Education and Practice

\author{
Azadeh \\ Kordestani Moghaddam' \\ Azim Mirzazadeh ${ }^{1-3}$ \\ 'Department of Medical Education, \\ School of Medicine, Tehran University of \\ Medical Sciences, Tehran, Iran; \\ ${ }^{2}$ Department of Medicine, School of \\ Medicine, Tehran University of Medical \\ Sciences, Tehran, Iran; ${ }^{3}$ Health \\ Professions Education Research Center \\ Tehran University of Medical Sciences, \\ Tehran, Iran
}

\begin{abstract}
Objectives: Medical Education Scholars Program (MESP) has been implemented with the aim of creating and enhancing the knowledge and skills of educational leaders and faculty members, as well as providing the basis for the development of training in academic departments at Tehran University of Medical Sciences.
\end{abstract}

Methods: The program planned for this 8-month course was offered in two sections. Fourteen faculty members participated in the two courses. The first part, which was a once-a-week workshop, included a 3-day workshop on "how to write a developmental proposal in education" and a 3-day "educational leadership" workshop. In the second part, which was a half-day course, was allocated to presenting the project progress report, the educational journal club, the workshops requested by participants on educational leadership, individual studies and counseling with mentors.

Results: In a poll, it was concluded that participants were satisfied with the curriculum of MESP and expressed that the program could not only expand their knowledge and skills on how to manage change and educational leadership, but also improve their viewpoint in this regard.

Conclusion: MESP can enhance the faculty members' knowledge and skills in their educational leadership and scholarly activities as a teacher, and increase their accountability as an educational leader. It seems that holding this program and similar programs is essential to improve the quality of education and educational leadership at universities.

Keywords: medical education, scholar program, educational leader

\section{Introduction}

Although the need to develop and enhance the teaching scholarly skills of faculty members in medical science education over the past 20 years have been defined well, there are some challenges considered by Lawrence, quoted from Rosenbaum et al. ${ }^{1}$ The most important of which is the need for experienced faculty members, capable of accepting the role of educational leadership in development programs. Hence, educational institutions should look for a way to develop accessible resources for education. In this regard, empowering institutions by increasing the number of expert medical educationalists who have the ability to transfer knowledge to their peers seems to be the best strategy. ${ }^{1}$ One of the programs planned to achieve this is the design and implementation of a Medical Education Scholars Program (MESP) that was designed in the 1990s and has been implemented in most of the world's major universities ever since. ${ }^{2}$
Correspondence: Azim Mirzazadeh

Department of Medical Education, School of Medicine, Tehran University of Medical

Sciences, Tehran, Iran

$\mathrm{Tel} / \mathrm{Fax}+9866939922$

Email mirzazad@tums.ac.ir 
Since many years ago, Tehran University of Medical Sciences (TUMS) has been transferring the basic concepts of medical education to the faculty members of the university through the "Basic Educational Skills" course. The need assessment on participants in courses and expert teachers of medical education revealed that since these courses teach the basic skills of medical education; fail to meet some of the essential needs of faculty members, such as education development, educational leadership, planning and educational evaluation. On the other hand, the only way of studying other medical education topics for the interested faculty members is attending a graduate degree in medical education, which seems to be impossible for a high percentage of faculty members due to its long duration.

In addition, some faculty members are unwilling to attend medical education in this vast volume. Therefore, it seems that the gap existing in this regard should be bridged through a medium-term course, which makes it possible to have more faculty members compared with that of the master's degree of medical education and is capable of transferring the necessary training skills for the development of education at college. The study on educational development programs of the world's major universities revealed that educational development skills are transferred with emphasis on the educational leadership role of faculty members through the MESP. ${ }^{1-6}$

The development of faculty members in the field of medical education and educational leadership, as well as the design and implementation developmental proposals in education at the university is of particular importance in the framework of the comprehensive faculty member empowerment program (teacher, leader and scholar training) of the university. Therefore, and due to the demands of the university in this regard, Education Development Center (EDC) has designed and implemented the program, at more specialized levels and within the framework of the comprehensive faculty empowerment program (teacher, leader and scholar training). Scholarly program for the teaching of medical education at different universities was studied, and this program has implemented in accordance with the needs of the faculty members and faculty empowerment comprehensive plan since 2015 .

Since one of the requirements for participation in the MESP is taking the course of basic educational skills or its equivalent successfully, the faculty members who participate in the program learn the basic concepts of the development of education in the basic educational skills course.
In this course, they will be given an opportunity to learn more advanced concepts, while also gaining the ability to acquire educational development skills, and getting prepared to take on the role of leadership in the respective faculty or department. In other words, it can be acknowledged that faculty members have learned the necessary training for a faculty member to develop their education after completing a course in MESP. Therefore, it is possible to specialize in MESP as a specialized course of midterm education, which can lead to the development of education at university and the development and promotion of educational leaders. Therefore, this study was carried out with the aim of investigating the effect of participation in the MESP on the educational development of faculty members and creating and developing educational leaders of TUMS.

\section{Methods}

This study was conducted between December 2015 and July 2017 at the EDC of TUMS. Fourteen faculty members (basic sciences and clinical sciences) participated in this program.

\section{Program details MESP management}

Planning, implementation and evaluation of MESP course in TUMS were conducted by the EDC. The curriculum of the course was designed by the Scientific Committee of the course based on the 10-question Harden model. ${ }^{7}$ Meetings and workshops were held by the director and the faculty members of the Medical Education department. Other meetings, including journal club meetings and educational seminars, as well as project progress report meetings, were presented by the faculty members participating in the course under the supervision and advice of the director and faculty members of the medical education department. The program was presented in about 8 months and in two sections.

\section{MESP participants}

Prior to the commencement of each course from the MESP, the announcement for admission was communicated via the EDC. Admission requests along with the MESP policies, procedures and curriculum of the program were communicated via e-mail to the managers of the Education Development Offices (EDO) and faculty members (available). The participants were introduced through the EDO and their educational resumes were studied. 
Participants in the program, who are members of the faculty of TUMS, should have the interest and motivation necessary to participate in the program and transfer the skills learned to other colleagues in addition to having taken a basic educational skills course or equivalent course successfully. The head of the department or the ward of hospital also agrees to participate in the program by allocating $4 \mathrm{hrs}$ of his/her weekly duty. The selection of the participants was based on the educational resume, group distribution, and facilities of the EDC by the Scientific Committee of the program. In the two MESP courses of the School of Medicine, 14 faculty members participated.

\section{Content and organizing the MESP program}

The content of the medical education in this program included the following:

1. Compilation, implementation and reporting of an educational development proposal

2. Leadership and Change Management

3. Educational Planning

4. Educational evaluation

Other items were also considered based on the needs and interests of the participants in the program. The program is presented in a longitudinal mode and in two sections.

Part 1. Each participant participated in the 3-day workshop educational development proposal as well as a 3-day workshop on educational, planning and educational evaluation leadership. The participants selected their educational development idea with the help and guidance of the faculty members of the workshop and considered drafting the proposed development plan within the time budget. At the beginning of the project, the participants were reminded to take Glassick et al's Six Criteria to Evaluate Scholarship (clear goals - appropriate preparation - appropriate methods - significant results - effective presentation - reflective critique) for the design and implementation of development projects. ${ }^{8}$ If desired, participants in the program could use the guidance of the teachers of the medical education group as a mentor along the way.

Part 2. The training program was $4 \mathrm{hrs}$ a week (half a day). From the mentioned $4 \mathrm{hrs}, 2 \mathrm{hrs}$ were allocated to participatein the educational programs and the remaining $2 \mathrm{hrs}$ were allotted to individual study and work on development projects selected by the members. At the end of the second part, participants participated in the scientific writing workshop.

\section{Strategies and educational methods}

The strategies used in the program were mainly community-based, elective, and systematic, based on learnercentered education, problem-based, integrated (vertical and horizontal integration) education.

The content of the training in the first part of the program was provided through planned workshops. In these workshops, the theoretical content was presented through interactive lectures and discussion in small groups. In addition, the opportunity for teamwork and practical activity was provided for participants in the workshop. The second part of the program was designed in such a way that the participants experienced different educational methods. For this purpose, the training sessions were organized in the form of educational seminars, workshops on request, project progress reports, consultation with mentors, and presentation and participation in the Journal Club meetings. Each participant selected and presented one of the important topics of the designated medical education in the sessions of the educational seminar and the journal club. In addition, participants were given the opportunity to participate in the meetings of the Medical Education department's Journal Clubs.

In the MESP, the participants were given the opportunity to attend educational sessions based on their needs and interests in the form of requested workshops, with the provision of content in these workshops mainly to the instructors of the program. The method of teaching in the workshops was similar to those of the first part of the program as an interactive lecture and discussion in small groups. Participants practiced practical writing of the educational development proposal provided in the first part of the program. In the second part of the project progress report sessions as well as the meetings with mentors, they discussed the issues that were encountered during the implementation of the development plan, and provided guidance on this. Also, individual study meetings and work on the project were considered so that the participants in these meetings, in addition to individual studying work practically on their own scholarly projects and conduct them.

\section{MESP evaluation}

The assessment of the instructors was done through the evaluation forms provided for this purpose and provided to the participants, while the program manager also, if necessary, received the oral feedback of the participants in relation to the program instructors. The criteria for evaluation of the learners' included: 1) active attendance in 
educational sessions; 2) the fulfillment of assignments; 3) design, implementation and evaluation of relevant educational development project; 4) presenting a research project paper in at least one of the regional medical education congresses in the form of oral presentation or posters; and 5) presenting an educational development project at Shahid Motahari Educational Festival.

\section{Results}

The evaluation of the program was performed based on the Kirkpatrick Model $^{9}$ to its third level.

\section{Reaction}

To this end, participants' satisfaction with the program was measured through a survey form and group discussion at the end of the program. The results indicate that they were satisfied with the MESP. They also said that not only did this program add to their knowledge and skills on how to manage change and educational leadership, but also it improved their vision. In addition, the participants stated that the participation in this program has enabled them to acquire the ability to carry out a development project in education from the beginning to the end. Besides, this program has provided the necessary competency to play the role of a leader in the form of department/group/ faculty/hospital.

\section{Learning}

Learning was assessed through reviewing the assignments provided by the participants during the program. The provided assignments were of a relatively proper level.

\section{Behavior}

Behavior was conducted by reviewing the educational development proposal drafted by the participants at the end of the program. Almost half of the participants in the course have managed to present one of the educational problems of their faculty or group in the form of a proposal for a development plan. One participant successfully completed and evaluated their educational development plan, which was also presented in the form of educational process at Shahid Motahari Educational Festival. In addition to reviewing and comparing the general evaluation of the proposals of the educational development plans of the participants in this program with other proposals of the educational development plans of the faculty members, the opinions and minor and major comments presented by the referees in this regard were also examined and compared.

\section{Outcomes}

The fourth level of Kirkpatrick's model emphasizes the evaluation of outcome in a larger context and focuses on the appropriate course of time. The study cannot be evaluated at this level. It can be considered in a separate study in the future.

\section{MESP challenges}

One of the most important challenges of the MESP is the long-term nature of the program and the emergence of some problems due to the overlap of the program time with the attendance at the hospital or faculty, especially for clinical faculty members. In spite of being informed about the time of the program before the beginning of the course and having the agreement of the head of the department or ward on participation in the program, it was not always possible for faculty members to attend some of the sessions. Another challenge is the likelihood of the presence of a limited number of faculty members in each round of the program, due to the limited number of instructors who can be used as mentors in the program.

\section{Discussion}

The main purpose of this study was to investigate the effect of participation in the MESP on the educational development of faculty members and creating and developing educational leaders. The results of our study showed that participants' satisfaction with the MESP, expanding their knowledge and skills in relation to change management and educational leadership, improving their view on the MESP, and helping them to develop a capacity for educational development proposal from beginning to end. As well as they stated that the program was able to help them acquiring the essential competency to change the role of leadership in the department/ward/faculty/hospital were some of the advantages of participating in this program. In addition, at least half of the participants have so far been able to provide one of the problems of their ward or department within the framework of a proposal for an educational development plan. In this regard, the National Educational Scholars Program (2006) in the US was implemented for pediatrician clinical education instructors with the aim of acquiring first-hand experience, skills and achievements in educational scholarship and their publication. Result of this program showed that participation in this 
program led to an increase in leadership activities, scholarly products, and academic promotion. ${ }^{10}$

Participants in the program also said that participation in this course will help improve the scholarly approach, educational scholarship, professional interactions, and their knowledge and educational skills. ${ }^{11}$ At the University of Michigan, this course was to develop educational leaders and empower and educate faculty members on curriculum management, promotion of education, educational research, development, and organizational leadership at all levels of medical education. It was revealed by before and after the course that participation in it led to further promotion and receiving educational grants, new educational responsibilities and new educational programs. One of the important results of this program was to provide, publish and receive educational grants related to educational scholarship. ${ }^{12}$

Graduates of the teaching scholarly program at the University of Washington in 2000 considered the program's benefits as individual professional development, extensive training programs at the institution or department, and improved professional performance. In addition, participation in the mentioned program had legitimized their coaching role and made it easier to implement innovations. ${ }^{2}$ According to an evaluation from the University of California, San Francisco, School of Medicine, the program also promotes knowledge and teaching skills, better understanding of curriculum and the development of academic programs. As well as, this program was caused by strengthening academic leadership skills, professional development, and collaborating in the form of a medical education network and participants' educational research. ${ }^{3}$

Although the nature of the MESP program is in such a way that it has to be designed and implemented in the long run, the mentioned issue was one of the challenges of our program. It seems to have been observed in similar programs in other universities, including the National Educational Scholars Program at US academic health centers. ${ }^{11}$ But, the other mentioned challenge was the lack of faculty members who could play the role mentors for the participants, which allowed fewer participants to attend each course, and somehow affected the successful implementation of this program and the fulfillment of the goals of the program. Chandrana et al considered this as one of the important factor in successful implementation of the program. Other factors were having an appropriate curriculum, taking into account tools tailored to the curriculum for organizing learners and documenting their efforts, supporting project-based learning through expert mentors, and facilitating communication and collaborations of learners with peers and teachers. $^{10}$

\section{Conclusion}

Participating in this program enhanced the knowledge and performance of participants in educational leadership. Although, given the findings of educational leadership results in the long run, it seems that a more accurate evaluation of the program might be achieved in the coming years. It seems that the study of the impact of the participation in the mentioned program on the role of leadership, accepting educational responsibilities and the accepted cases in Shahid Motahari Festival should be considered annually. Furthermore, the impact of the program on how to play the leadership roles in each participant should be studied 5years after the program.

\section{Disclosure}

The authors report no conflicts of interest in this work.

\section{References}

1. Rosenbaum ME, Lenoch S, Ferguson KJ. Outcomes of a Teaching Scholars program to promote leadership in faculty development. Teach Learn Med. 2005;17:247-253.

2. Robins L, Ambrozy D, Pinsky LE. Promoting academic excellence through leadership development at the University of Washington: the teaching scholars program. Acad Med. 2006;81(11):979-983. doi:10.1097/01.ACM.0000242584.11488.4e

3. Muller JH, Irby DM. Developing educational leaders: the teaching scholars program at the University of California, San Francisco, School of Medicine. Acad Med. 2006;81(11):959-964. doi:10.1097/ 01.ACM.0000242588.35354.db

4. Steinert Y, McLeod PJ. From novice to informed educator: the teaching scholars program for educators in the health sciences. Acad Med. 2006;81 (11):969-974. doi:10.1097/01.ACM.0000242593.29279.be

5. Steinert Y, Nasmith L, McLeod PJ, Conochie L. A teaching scholars program to develop leaders in medical education. Acad Med. 2003;78 (2):142-149.

6. Fidler DC, Khakoo R, Miller LA. Teaching scholars programs: faculty development for educators in the health professions. Acad Psychiatry. 2007;31(6):472-478. doi:10.1176/appi.ap.31.6.472

7. Harden RM. Ten questions to ask when planning a course or curriculum. Med Educ. 1986;20(4):356-365.

8. Fincher R-ME, Simpson DE, Mennin SP, et al. Scholarship in teaching: an imperative for the 21st century. Acad Med. 2000;75 (9):887-894.

9. Kikpatrick D, Kikpatrick J. Kikpatrick four levels. Audio recordings study guide. Kikpatrick Partners. 2013:6-14.

10. Chandran L, Gusic ME, Lane JL, Baldwin CD. Designing a national longitudinal faculty development curriculum focused on educational scholarship: process, outcomes, and lessons learned. Teach Learn Med. 2017;29(3):337-350. doi:10.1080/10401334.2017.1282370 
11. Baldwin CD, Gusic ME, Chandran L. The impact of a national faculty development program embedded within an academic professional organization. Acad Med. 2017;92(8):1105-1113. doi:10.1097/ ACM.0000000000001496
12. Gruppen LD, Frohna AZ, Anderson RM, Lowe KD. Faculty development for educational leadership and scholarship. Acad Med. 2003;78(2):137-141.

\section{Publish your work in this journal}

Advances in Medical Education and Practice is an international, peerreviewed, open access journal that aims to present and publish research on Medical Education covering medical, dental, nursing and allied health care professional education. The journal covers undergraduate education, postgraduate training and continuing medical education including emerging trends and innovative models linking education, research, and health care services. The manuscript management system is completely online and includes a very quick and fair peer-review system. Visit http://www.dovepress.com/testimonials.php to read real quotes from published authors. 